\title{
Knee osteoarthritis, lumbar-disc degeneration and developmental dysplasia of the hip - an emerging genetic overlap
}

\author{
John Loughlin* \\ See related research by Shi et al., http://arthritis-research.com/content/13/1/R27
}

\begin{abstract}
Genetics highlights relationships between biological systems, and as the number of defined osteoarthritis susceptibility alleles increases, there is the natural tendency to assess whether the alleles influence other musculoskeletal phenotypes. That has proven to be the case for the GDF5 polymorphism rs143383, a risk factor for knee osteoarthritis and several other common conditions, including lumbar-disc degeneration and developmental dysplasia of the hip. Another interesting example has recently emerged in the repeat polymorphism of the asporin gene, ASPN, which is also associated with these three phenotypes. Such discoveries increase our understanding of shared disease etiology but also emphasize the complexity of common genetic risk.
\end{abstract}

Pleiotropy refers to the capacity of a DNA mutation to have an effect on many biological systems and is a consequence of the fact that, during life, gene products are typically expressed, as so-called spatial and temporal effects, in a variety of cell types at a number of different times. Pleiotropy of common alleles is an expected feature of human diseases that have a major genetic component and manifests as an allele associated with several different phenotypes. The musculoskeletal system is no exception and in the previous issue of Arthritis Research $\mathcal{E}$ Therapy Shi and colleagues [1] brought another example to our attention. In their study of Han Chinese, the investigators reported an association of the

*Correspondence: john.loughlin@ncl.ac.uk

Musculoskeletal Research Group, Institute of Cellular Medicine, Newcastle University, 4th Floor, Catherine Cookson Building, The Medical School, Framlington Place, Newcastle upon Tyne, NE2 4HH, UK
D-repeat polymorphism of the asporin gene, $A S P N$, with developmental dysplasia of the hip (DDH). This polymorphism had originally shown an association with knee osteoarthritis (OA) and subsequently with lumbardisc degeneration (LDD), also in Asian cohorts [2,3].

Asporin is an extracellular matrix (ECM) macromolecule belonging to the small leucine-rich proteoglycan (SLRP) protein family. SLRP family members are able to bind other structural components of the ECM, such as collagen, as well as growth factors that temporarily reside in the ECM, such as members of the transforming growth factor-beta (TGF- $\beta$ ) superfamily. Asporin is present in a number of tissues, including cartilage, and the D-repeat polymorphism of $A S P N$ resides within exon 2 of the gene. It gets its name from the fact that it is a triplet repeat coding for a polymorphic stretch of residues of aspartic acid ( $D$ is the one-letter code for this particular amino acid). Depending on the ethnic group, the repeat has up to 12 alleles encoding 8 to $19 \mathrm{D}$ residues.

In the original OA association study, it was reported that the allele coding for 14 D-repeats (D14) was a risk allele for knee OA [2]. This was also the case for LDD [3] and is the case in the recent DDH study [1]. Furthermore, the D13 allele was found to be protective for knee OA, something also observed for DDH. OA and LDD can be viewed as having similar etiological routes, both of which involve degeneration of cartilage, albeit of different types; that of OA is hyaline and that of LDD is fibrocartilage. They are also diseases associated with aging. However, $\mathrm{DDH}$ is not associated with aging but is instead congenital, nor is it a degenerative disease but instead involves the displacement of the proximal femur from the acetabulum.

What is particularly intriguing, therefore, is how the same alleles at the ASPN D-repeat contribute to phenotypes as different as OA/LDD and DDH. Functional studies have suggested that asporin attenuates TGF- $\beta$ signaling and that the extent of the attenuation is influenced by the number of D-repeats $[2,4,5]$. Perhaps, 
therefore, the D-repeat genotype, with its ability to alter the length of the run of aspartic acids, combined with expected differences in the expression levels of the various members of the TGF- $\beta$ superfamily during development and in mature tissues, influences which skeletal sites are affected and which phenotypes result.

The reality will obviously be far more complex than this. For example, being influenced by genotypes at other loci and by non-genetic factors, the association of the D-repeat with OA, LDD, and DDH is far from penetrant. This is apparent when one recalls that, although the D-repeat can have an impact on knee OA in Asians, it does not contribute to knee OA in Europeans: genetic or non-genetic factors must account for this ethnic difference [6]. Furthermore, the D-repeat is associated with an aberrant hip shape that results in DDH in the young but is not associated with an increased risk of hip $\mathrm{OA}$ in older patients; in the latter, the effect on hip OA is presumably a temporal one.

Another example in the literature of pleiotropy of an $\mathrm{OA}$ locus is the single-nucleotide polymorphism rs143383, which is located in the 5' untranslated region of GDF5. This gene codes for the TGF- $\beta$ superfamily member growth and differentiation factor 5 . Like the $A S P N$ D-repeat, rs143383 was first reported to be associated with increased risk of large-joint OA, principally of the knee [7]. rs143383 was then shown to be associated with other joint-related disease phenotypes, including DDH and LDD [8-10]. There are, therefore, striking similarities between the D-repeat and rs143383 associations; the obvious similarity is that when it comes to lower-limb OA, both variants are particularly relevant to knee disease, but when it comes to early development, the hip is the main repository of the genetic effect. We shall have to wait for the discovery of additional susceptibility alleles to assess whether this shared genetic risk between OA, LDD, and DDH is more widespread or whether it is restricted to members of the TGF- $\beta$ signaling pathway. One thing that we can be certain of is that late-onset musculoskeletal diseases can inform our understanding of developmental conditions, and vice versa.

Abbreviations

ASPN, the asporin gene; DDH, developmental dysplasia of the hip; ECM, extracellular matrix; LDD, lumbar-disc degeneration; OA, osteoarthritis; SLRP, small leucine-rich proteoglycan; TGF- $\beta$, transforming growth factor-beta.
Competing interests

The author declares that he has no competing interests.

\section{Acknowledgments}

The author acknowledges the support of Arthritis Research UK, the UK NIHR Biomedical Research Centre for Ageing and Age-Related Disease award to the Newcastle upon Tyne Hospitals NHS Foundation Trust, and the Oliver Bird Rheumatism Programme.

Published: 19 April 2011

\section{References}

1. Shi D, Dai J, Zhu P, Qin J, Zhu L, Zhu H, Zhao B, Qiu X, Xu Z, Chen D, Yi L, Ikegawa $S$, Jiang Q: Association of the $D$ repeat polymorphism in the ASPN gene with developmental dysplasia of the hip: a case-control study in Han Chinese. Arthritis Res Ther 2011, 13:R27.

2. Kizawa H, Kou I, lida A, Sudo A, Miyamoto Y, Fukuda A, Mabuchi A, Kotani A, Kawakami A, Yamamoto S, Uchida A, Nakamura K, Notoya K, Nakamura Y, Ikegawa S: An aspartic acid repeat polymorphism in asporin inhibits chondrogenesis and increases susceptibility to osteoarthritis. Nat Genet 2005, 37:138-144.

3. Song YQ, Cheung KM, Ho DW, Poon SC, Chiba K, Kawaguchi Y, Hirose Y, Alini M, Grad S, Yee AF, Leong JC, Luk KD, Karppinen J, Cheah KS, Sham P, Ikegawa S, Chan D: Association of the asporin D14 allele with lumbar-disc degeneration in Asians. Am J Hum Genet 2008, 82:744-747.

4. Nakajima M, Kizawa H, Saitoh M, Kou I, Miyazono K, Ikegawa S: Mechanisms for asporin function and regulation in articular cartilage. J Biol Chem 2007, 282:32185-32192.

5. Kou I, Nakajima M, Ikegawa S: Binding characteristics of the osteoarthritisassociated protein asporin. J Bone Miner Metab 2010, 28:395-402.

6. Nakamura T, Shi D, Tzetis M, Rodriguez-Lopez J, Miyamoto Y, Tsezou A, Gonzales A, Jiang Q, Kamatani N, Loughlin J, Ikegawa S: Meta-analysis of association between the ASPN D-repeat and osteoarthritis. Hum Mol Genet 2007, 16:1676-1681.

7. Chapman K, Takahashi A, Meulenbelt I, Watson C, Rodriguez-Lopez J, Egli R, Tsezou A, Malizos KN, Kloppenburg M, Shi D, Southam L, van der Breggen R, Donn R, Qin J, Doherty M, Slagboom PE, Wallis G, Kamatani N, Jiang Q, Gonzalez A, Loughlin J, Ikegawa S: A meta-analysis of European and Asian cohorts reveals a global role of a functional SNP in the 5'UTR of GDF5 with osteoarthritis susceptibility. Hum Mol Genet 2008, 17:1497-1504.

8. Dai J, Shi D, Zhu P, Qin J, Ni H, Xu Y, Yao C, Zhu L, Zhu H, Zhao B, Wei J, Liu B, Ikegawa S, Jiang Q, Ding Y: Association of a single nucleotide polymorphism in growth differentiate factor 5 with congenital dysplasia of the hip: a case-control study. Arthritis Res Ther 2008, 10:R126.

9. Rouault K, Scotet V, Autret S, Gaucher F, Dubrana F, Tanguy D, El Rassi CY, Fenoll B, Férec C: Evidence of association between GDF5 polymorphisms and congenital dislocation of the hip in a Caucasian population. Osteoarthritis Cartilage 2010, 18:1144-1149.

10. Williams F, Popham M, Hart D, de Schepper E, Bierma-Zeinstra S, Hofman A, Uitterlinden AG, Arden N, Cooper C, Spector T, Valdes A, van Meurs J: GDF5 SNP rs143383 is associated with lumbar disc disease in northern European women. Arthritis Rheum 2010 Dec 2. [Epub ahead of print].

doi:10.1186/ar3291

Cite this article as: Loughlin J: Knee osteoarthritis, lumbar-disc degeneration and developmental dysplasia of the hip - an emerging genetic overlap. Arthritis Research \& Therapy 2011, 13:108. 